\title{
Pharmacokinetic Concentration Completion Status
}

National Cancer Institute

\section{Source}

National Cancer Institute. Pharmacokinetic Concentration Completion Status. NCI

Thesaurus. Code C113374.

A term used to describe the state or condition of the completeness of the pharmacokinetic concentration data. 